\title{
Eficiência de Glyphosate no Controle de Commelina benghalensis e Commelina diffusa ${ }^{1}$
}

\author{
Efficiency of Glyphosate in the Control of Commelina benghalensis and \\ Commelina diffusa
}

\begin{abstract}
SANTOS, I.C. ${ }^{2}$, SILVA, A.A. ${ }^{3}$, FERREIRA, F.A. ${ }^{3}$, MIRANDA, G.V. ${ }^{3}$ e PINHEIRO, R.A.N. ${ }^{4}$
RESUMO - A planta daninha trapoeraba (Commelina spp.) possui grande capacidade de sobreviver em ambientes diversificados, o que dificulta o seu controle. Em cafezais da Zona da Mata de Minas Gerais, onde o herbicida glyphosate é aplicado repetidamente, as espécies Commelina benghalensis e $C$. diffusa têm apresentado tolerância a este herbicida. Para confirmar esse fato e verificar o efeito de doses crescentes de glyphosate $(720,1.440,2.160,2.880$ e 3.600 g i.a. ha ${ }^{-1}$ ) no controle dessas duas espécies de plantas daninhas, instalou-se um experimento no delineamento experimental de blocos casualizados, com seis repetições. As doses do herbicida foram aplicadas no período de florescimento de plantas de trapoeraba cultivadas em caixas de polietileno com dimensões de $10 \mathrm{~cm}$ de altura, 27,5 cm de largura e $39,5 \mathrm{~cm}$ de comprimento, em ambiente desprotegido. A eficácia dos tratamentos foi avaliada por meio da porcentagem de controle em relação à testemunha e da biomassa seca da parte aérea que sobreviveu aos tratamentos. C. benghalensis foi eficientemente controlada pelo glyphosate, mas $C$. diffusa apresentou tolerância. Para $C$. benghalensis o controle foi acima de 94\% a partir da menor dose, 25 dias após tratamento (DAT) e de 100\% em todas as doses aos 63 DAT. Para $C$. diffusa, em geral, quanto maior a dose de glyphosate, menor a biomassa seca da parte aérea. Entretanto, mesmo nas três maiores doses, nas quais se observou, aos 46 DAT, até $98,3 \%$ de controle, constatou-se regeneração de plantas aos 88 DAT. Nas condições do experimento, o glyphosate proporcionou excelente controle de $C$. benghalensis a partir de 720 g i.a. ha ${ }^{-1}, 25$ DAT. Contudo, excelente controle de C. diffusa por mais de 60 dias só foi obtido a partir de 2.880 g i.a. ha ${ }^{-1}$ de glyphosate..
\end{abstract}

Palavras-chave: trapoeraba, controle químico, tolerância.

\begin{abstract}
The weed dayflower, Commelina spp., can survive in a great diversity of environments, what makes its control difficult. In coffee plantations of the Zona da Mata, Minas Gerais - Brazil, glyphosate is repeatedly applied to control weeds, but Commelina benghalensis and C. diffusa have not been successfully controlled. To confirm such fact and to verify the effect of increasing doses of glyphosate $\left(720,1,400,2,160,2,880\right.$ and 3,600 $\mathrm{g}$ a.i. ha $\mathrm{h}^{-1}$ ) on these weed species, an experiment was installed in a randomized block design with six replications. The rates of herbicide were applied in the flowering period of plants grown in polyethylene boxes $10 \mathrm{~cm}$ high, $27.5 \mathrm{~cm}$ wide and $39.5 \mathrm{~cm}$ long, in unprotected environment. The effectiveness of the treatments was evaluated through the percentage of weed control related to the check treatment (no herbicide), and by the shoot dry biomass that survived the treatments. C. benghalensis was efficiently controlled by glyphosate, but C. diffusa presented herbicide tolerance. The control of C. benghalensis was above 94\%, starting from the smallest rate, 25 days after treatments (DAT), and it was $100 \%$ in all the doses at 63 DAT. For C. diffusa, in general, as the doses of glyphosate increased, the shoot dry biomass became smaller. However, even with the three higher doses, when up to $98.3 \%$ of control at 46 DAT was observed, plant recovery occurred at 88 DAT. Under the conditions of this experiment, glyphosate provided an excellent control of $\mathbf{C}$. benghalensis starting from $720 \mathrm{~g}$ a.i. ha ${ }^{-1}, 25$ DAT. However, excellent control of C. diffusa for over 60 DAT was only achieved with glyphosate rate starting from $2.880 \mathrm{~g}$ a.i. ha ${ }^{-1}$.
\end{abstract}

Key words: dayflower, chemical control, tolerance.

1 Recebido para publicação em 10/11/2000 e na forma revisada em 13/3/2001.

Parte da dissertação de Tese de Doutorado apresentada à Universidade Federal de Viçosa.

2 Pesquisadora, Empresa de Pesquisa Agropecuária de Minas Gerais - Centro Tecnológico da Zona da Mata, Caixa Postal 216, 36571-000 Viçosa-MG. ${ }^{3}$ Professor, Departamento de Fitotecnia da Universidade Federal de Viçosa, 36571-000 Viçosa-MG.

${ }^{4}$ Engenheiro-Agrônomo. 


\section{INTRODUÇÃO}

O Estado de Minas Gerais é hoje o maior produtor de café do País, com um parque cafeeiro de um milhão de hectares, 2,5 bilhões de cafeeiros e produção de 14 milhões de sacas beneficiadas (ITEM, 2000). Uma das causas de diminuição da produtividade de cafezais é a competição entre cafeeiros e plantas daninhas. A flora daninha presente nos cafezais é muito diversificada, mas no mercado existe grande número de herbicidas que têm potencial para controlar eficientemente a maioria dessas plantas. No entanto, seja pela utilização (dose/ aplicação) incorreta, seja pela escolha inadequada do produto ou mesmo pela utilização ininterrupta de produtos com o mesmo princípio ativo, algumas plantas daninhas têm escapado às aplicações de herbicidas. Por exercer efetivo controle de grande número de plantas daninhas mono e dicotiledôneas, perenes e anuais, sem ser ambientalmente agressivo, o glyphosate (N-(fosfonometil)glicina) é o herbicida mais conhecido no mundo (Malik et al., 1989). No Brasil, o uso do glyphosate nas culturas de café e citros vem aumentando desde seu registro em 1973, sendo hoje um dos herbicidas mais utilizados nessas culturas, entre outras. Entretanto, o uso contínuo de um mesmo herbicida ou de diferentes herbicidas com o mesmo mecanismo de ação favorece o aumento da população de plantas daninhas resistentes a esses herbicidas (Christoffoleti et al., 1994). Apesar de os herbicidas inibidores da EPSPs serem considerados produtos com baixa probabilidade de selecionar genótipos resistentes (Vargas et al., 1999), na literatura científica encontram-se exemplos de variação na suscetibilidade de plantas daninhas ao glyphosate.

No Brasil, Durigan et al. (1988) e Galli (1991) relatam que a aplicação de glyphosate em pomares cítricos do Estado de São Paulo, isoladamente e nas doses recomendadas, tem proporcionado a seleção da trapoeraba (Commelina virginica), o que os autores atribuem à grande tolerância desta ao glyphosate e à eliminação da competição com outras plantas daninhas. De acordo com Vargas et al. (1999), espécies do gênero Commelina apresentam alta tolerância aos inibidores da EPSPs, o que não significa que sejam resistentes; especula-se que essa tolerância esteja relacionada com a insensibilidade da EPSPs destas espécies ao herbicida.

Apesar de a espécie $C$. benghalensis ser a mais citada nas literaturas nacional e internacional, em cafezais da Zona da Mata de Minas Gerais uma outra espécie - C. diffusa foi identificada ocorrendo juntamente com C. benghalensis. Em áreas onde o herbicida glyphosate vem sendo usado repetidamente, ambas têm escapado ao controle químico.

Morfologicamente, as duas espécies são facilmente distinguíveis. $C$. benghalensis exibe folhas subpecioladas, ovóides, com bases atenuadas e ápices obtusos a agudos, de cor verdeclara e com vilosidade em ambas as faces, enquanto $C$. diffusa exibe folhas sésseis, com lâminas lineares, ovóides ou oblongas, bases ligeiramente arredondadas, ápices acuminados, de cor verde-escura, glabras em ambas as faces. As espatas da primeira são brevipedunculadas, triangulares e agrupadas no ápice do ramo; as da segunda são longopedunculadas, ovóides e de ápices acuminados (Barreto, 1997). Além disso, arrancando com cuidado plantas que já passaram pelo estágio reprodutivo, percebe-se, a partir dos rizomas, a formação de frutos subterrâneos, oriundos de flores cleistogâmicas, característicos de C. benghalensis.

O objetivo deste trabalho foi verificar o efeito de doses crescentes de glyphosate no controle de duas espécies de trapoeraba: $C$. benghalensis e $C$. diffusa.

\section{MATERIAL E MÉTODOS}

O experimento foi conduzido em 1999, en ambiente desprotegido, na Estação Experimental Diogo Alves de Melo, campus da UFV, em caixas de polietileno de $27,5 \mathrm{~cm}$ de largura por $39,5 \mathrm{~cm}$ de comprimento e $10 \mathrm{~cm}$ de altura, que foram preenchidas com $10 \mathrm{~kg}$ de substrato constituído de $2 / 3$ de material de solo, $1 / 3$ de composto orgânico, calcário e adubo mineral, 30 dias antes do plantio.

Pedaços de ramos de plantas de Commelina diffusa e Commelina benghalensis, coletados em cafezais de Muriaé e Ponte Nova-MG, respectivamente, foram multiplicados em casa de 
vegetação. Das plantas matrizes de cada acesso retiraram-se segmentos de caule de $15 \mathrm{~cm}$ de comprimento, contendo em média quatro nós. Nessa ocasião (16 de abril), C. diffusa encontrava-se em estágio vegetativo e $C$. benghalensis em estágio reprodutivo. Foram plantadas nove estacas em cada caixa, enterrando-se um dos nós, e o substrato foi irrigado sempre que necessário. As estacas das duas espécies apresentaram $100 \%$ de pegamento, mas C. diffusa produziu maior volume de biomassa que C. benghalensis. Entretanto, mesmo entre caixas da mesma espécie o crescimento das plantas variou muito. Por isso, foram organizados blocos de acordo com o volume de biomassa. Assim, o bloco 1 foi formado com as caixas contendo plantas de maior biomassa e o bloco 6 com as caixas de menor biomassa. Os tratamentos consistiram de seis doses de glyphosate $(0,720,1.440,2.160,2.880 \mathrm{e}$ $3.600 \mathrm{~g} \mathrm{ha}^{-1}$ ), aplicadas como solução aquosa de Roundup (contendo $360 \mathrm{~g} \mathrm{~L}^{-1}$ de glyphosate) sobre as duas espécies de trapoeraba no período de florescimento (77 dias após plantio), no delineamento de blocos casualizados, com seis repetições. Utilizou-se um pulverizador costal de precisão, propelido a gás carbônico, munido de barra com dois bicos tipo leque 110.03,

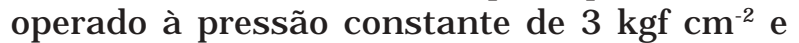
volume de calda correspondente a $200 \mathrm{~L} \mathrm{ha}^{-1}$. A aspersão foi realizada sobre as caixas enfileiradas, começando pela dose mais baixa, com início às $8 \mathrm{~h} 40 \mathrm{~min}$, na ausência de vento, estando a temperatura do ar a $20{ }^{\circ} \mathrm{C}$.

Avaliou-se a eficácia dos tratamentos por meio da porcentagem de controle e da biomassa seca da parte aérea que sobreviveu aos tratamentos. A porcentagem de controle foi avaliada visualmente em relação à testemunha (dose 0) de cada bloco, aos 25, 46, 63 e 88 dias após a aplicação dos tratamentos. Em seguida, a biomassa seca foi obtida após a secagem da parte aérea das plantas de cada caixa, em estufa com ventilação forçada de ar a $\pm 75{ }^{\circ} \mathrm{C}$, até peso constante. Como a espécie $C$. benghalensis produz sementes subterrâneas, após a morte da parte aérea devido aos tratamentos, pôde-se contar o número de plântulas emergidas em cada caixa (área $=0,108 \mathrm{~m}^{2}$ ), o que dá uma idéia do potencial de reinfestação dessa espécie.

As pressuposições da análise de variância foram atendidas para arco-seno da raiz quadrada de porcentagem de controle dividido por cem, logaritmo neperiano de biomassa seca e número de plântulas. Na análise de variância da porcentagem de controle e do número de plântulas, os dados da testemunha (dose 0) foram desprezados, enquanto na análise de biomassa seca estes dados foram considerados. Para a primeira época de avaliação, as fontes de variação da análise de variância foram blocos, espécies de trapoeraba, doses de glyphosate, interação espécie x doses e resíduo. Para as outras épocas foi realizada a análise de variância sem as fontes de variação espécie e espécie $\mathrm{x}$ doses e apenas para a espécie C. diffusa, pois as variáveis aleatórias porcentagem de controle e biomassa seca de C. benghalensis não apresentaram variância entre e dentro de doses devido à morte de todas as plantas, causada pelos tratamentos. Para o efeito quantitativo (doses de glyphosate), foi realizada análise de regressão escolhendo-se o modelo que apresentou significância, desvio da regressão não-significativo, maior $\mathrm{R}^{2} \mathrm{e}$ sentido biológico.

\section{RESULTADOS E DISCUSSÃO}

A análise de variância dos dados de porcentagem de controle transformados, coletados aos 25 DAT (dias após aplicação dos tratamentos), revelou efeito significativo das espécies de trapoeraba e das doses de glyphosate e ausência de efeito para a interação espécies x doses (Tabela 1). Nas condições do experimento, para ambas as espécies, quanto maior a dose de glyphosate, maior a porcentagem de controle para doses compreendidas entre 720 e $3.600 \mathrm{~g} \mathrm{ha}^{-1}$, ajustando-se o modelo linear para tal efeito (Figura 1).

Dado o eficiente controle de C. benghalensis pelo glyphosate, a partir da segunda avaliação (46 DAT), os dados referentes a esta espécie não atenderam às pressuposições da análise de variância (não apresentaram variância entre as repetições nem entre as três maiores doses aos 46 DAT e entre todas as doses aos 63 e 88 DAT). As análises de variância para as épocas 46, 63 e 88 DAT indicaram efeitos significativos das doses de glyphosate sobre a porcentagem de controle de C. diffusa (Tabela 2), ajustando-se o modelo quadrático para tal efeito nas três épocas (Figura 2). Isto indica a 
eficiência significativa do herbicida no controle de $C$. benghalensis, mas não de $C$. diffusa, independentemente da dose no intervalo entre 720 e $3.600 \mathrm{~g} \mathrm{ha}^{-1}$.

Tabela 1 - Análise de variância dos dados de porcentagem de controle de plantas de $C$. diffusa e $C$. benghalensis, transformados $\left(\operatorname{arcsen}(\% / 100)^{1 / 2}\right), 25$ dias após aplicação do glyphosate

\begin{tabular}{|l|r|c|r|r|}
\hline \multicolumn{1}{|c|}{ FV } & GL & SQ & QM & \multicolumn{1}{c|}{ F } \\
\hline Bloco & 5 & 0,034758 & 0,006952 & $0,60 * *$ \\
Espécie & 1 & 2,127909 & 2,127909 & $182,23 * *$ \\
Doses & 4 & 0,682974 & 0,170743 & $14,62 * *$ \\
Linear & 1 & 0,635917 & 0,635917 & $54,46 * *$ \\
Quadrático & 1 & 0,003637 & 0,003637 & $0,31^{\text {n.s. }}$ \\
Desvios & 3 & 0,047056 & 0,015685 & $1,03^{\text {n.s. }}$ \\
Espécie x Dose & 4 & 0,048106 & 0,012026 & $1,03^{\text {n.s. }}$ \\
\hline Resíduo & 45 & 0,525468 & 0,011677 & \\
\hline
\end{tabular}

n.s. Não-significativo a $5 \%$ de probabilidade pelo teste de F.

** Significativo a $1 \%$ de probabilidade pelo teste de F;

$\mathrm{CV}=8,38 \%$.

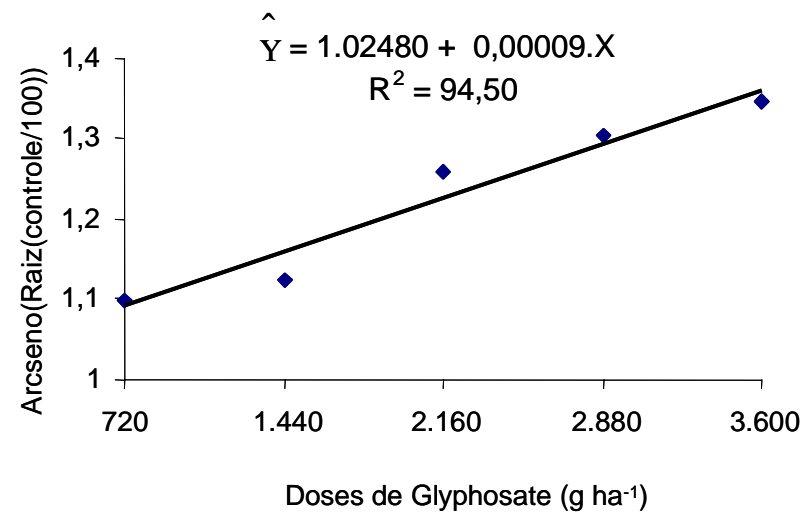

Figura 1 - Equação estimada dos dados de porcentagem de controle de plantas de $C$. diffusa e C. benghalensis, transformados $\left\{\operatorname{arcsen}(\% / 100)^{1 / 2}\right\}$, aos 25 dias após aplicação do glyphosate.

A Tabela 3 mostra as médias das porcentagens de controle (dados originais) de C. diffusa e C. benghalensis, em relação à testemunha de cada bloco. Confirmando os resultados anteriores, pode-se constatar que $C$. benghalensis foi muito mais sensivel aos tratamentos do que C. diffusa. Enquanto C. benghalensis, aos 25 DAT, na menor dose, apresentava mais de 94\% de controle, C. diffusa alcançou tais percentuais aos 46 DAT, com a aplicação de 2.160,
2.880 e $3.600 \mathrm{~g} \mathrm{ha}^{-1}$ de glyphosate, mas revelou sinais de recuperação aos 88 DAT, devido às menores porcentagens de controle em relação às épocas anteriores. Aos 63 DAT, todas as parcelas de $C$. benghalensis, excetuando a testemunha, apresentavam 100\% de controle, ou seja, não havia parte aérea sobre o substrato.

Tabela 2 - Análise de variância dos dados de porcentagem de controle de plantas de $C$. diffusa, transformados (arcsen $\left.(\% / 100)^{1 / 2}\right)$, aos 46, 63 e 88 dias após aplicação do glyphosate

\begin{tabular}{|l|c|l|l|c|}
\hline \multirow{2}{*}{ FV } & \multirow{2}{*}{ GL } & \multicolumn{3}{|c|}{ Quadrados Médios } \\
\cline { 3 - 6 } & & \multicolumn{1}{|c|}{46 DAT } & 63 DAT & 88 DAT \\
\hline Bloco & 5 & $0,006451^{\text {n.s. }}$ & $0,005234^{\text {n.s. }}$ & $0,010504^{\text {n.s. }}$ \\
Doses & 4 & $0,145107^{* *}$ & $0,212737^{* *}$ & $0,392553^{* *}$ \\
Linear & 1 & $0,476849^{* *}$ & $0,212737^{* *}$ & $1,391840^{* *}$ \\
Quadrático & 1 & $0,089124^{* *}$ & $0,019451^{* *}$ & $0,092518^{* *}$ \\
Desvios & 2 & 0,007229 & 0,009973 & $0,042927^{\text {n.s. }}$ \\
\hline Resíduo & 20 & 0,009886 & 0,003448 & 0,016377 \\
\hline CV & & 7,48 & 4,50 & 11,62 \\
\hline
\end{tabular}

n.s. Não-significativo a $5 \%$ de probabilidade pelo teste de F.

** Significativo a $1 \%$ de probabilidade pelo teste de $\mathrm{F}$.

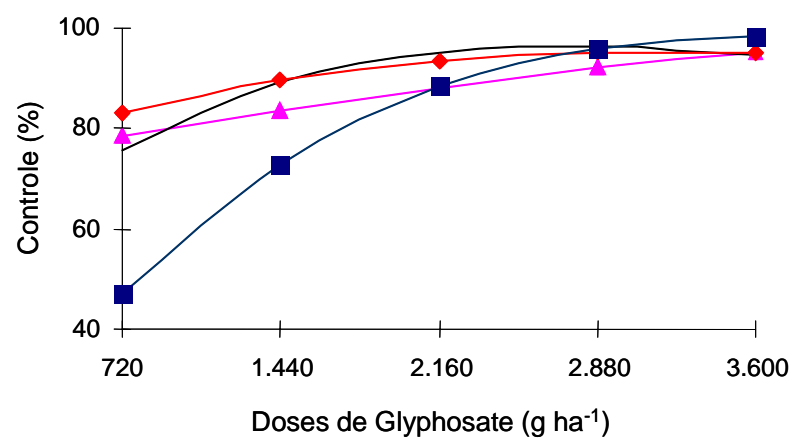
$\longleftarrow 25$ DAT -46 DAT $\bullet 63$ DAT $\neg-88$ DAT

\begin{tabular}{|c|c|c|}
\hline Época & Equação & $R^{2}$ \\
\hline 25 DAT & $\hat{\mathrm{Y}}=1,0248+0,00009 \mathrm{X}$ & 95,00 \\
\hline 46 DAT & $\hat{\mathrm{Y}}=0,8042+0,0002 \mathrm{X}-0,00000007 \mathrm{X}^{2}$ & 98,00 \\
\hline 63 DAT & $\hat{\mathrm{Y}}=1,0160+0,0004 \mathrm{X}-0,00000003 \mathrm{X}^{2}$ & 93,00 \\
\hline 88 DAT & $\hat{\mathrm{Y}}=0,4261+0,0005 \mathrm{X}-0,00000006 \mathrm{X}^{2}$ & 95,00 \\
\hline
\end{tabular}

Figura 2 - Equações estimadas dos dados de porcentagem de controle de plantas de $C$. diffusa, transformados (arcsen $\left.(\% / 100)^{1 / 2}\right)$, aos 25, 46, 63 e 88 dias após aplicação dos tratamentos (DAT). 
Tabela 3 - Porcentagem de controle* da trapoeraba em função de doses de glyphosate e épocas de avaliação, em DAT (média de seis blocos)

\begin{tabular}{|c|c|c|c|c|c|c|c|c|}
\hline \multirow{3}{*}{$\begin{array}{l}\text { Glyphosate } \\
\left(\text { g i.a. ha }{ }^{-1}\right)\end{array}$} & \multicolumn{8}{|c|}{ Espécie } \\
\hline & \multicolumn{4}{|c|}{ Commelina diffusa } & \multicolumn{4}{|c|}{ Commelina benghalensis } \\
\hline & 25 DAT & 46 DAT & 63 DAT & 88 DAT & $25 \mathrm{DAT}$ & 46 DAT & $63 \mathrm{DAT}$ & $88 \mathrm{DAT}$ \\
\hline 720 & 64,17 & 77,17 & 85,00 & 48,33 & 94,50 & 97,83 & 100,00 & 100,00 \\
\hline 1.440 & 65,83 & 89,50 & 88,33 & 60,00 & 97,00 & 98,83 & 100,00 & 100,00 \\
\hline 2.160 & 82,50 & 97,66 & 96,00 & 86,50 & 98,67 & 100,00 & 100,00 & 100,00 \\
\hline 2.880 & 86,33 & 98,00 & 96,67 & 93,33 & 99,83 & 100,00 & 100,00 & 100,00 \\
\hline 3.600 & 90,00 & 98,33 & 96,67 & 93,16 & 100,00 & 100,00 & 100,00 & 100,00 \\
\hline
\end{tabular}

* 91 a $100 \%$ de controle $=$ excelente; 81 a $90 \%$ de controle $=$ bom; 71 a $80 \%$ de controle $=$ razoável; 50 a $70 \%$ de controle $=$ ruim; $<50 \%$ de controle $=$ insuficiente

Segundo Prado Filho e Carvalho (1980), o glyphosate a 360,720 e $1.440 \mathrm{~g} \mathrm{ha}^{-1}$ proporcionou controle excelente de Cenchrus echinatus e Commelina spp. por um período de 30 dias, com reinfestação a partir de 40 dias; somente a mistura glyphosate $+2,4-\mathrm{D}+$ diuron é que proporcionou controle de $100 \%$ até 60 DAT.

A ação do glyphosate aplicado isoladamente a 650 e $1.300 \mathrm{~g} \mathrm{ha}^{-1}$ proporcionou controle muito baixo de $C$. virginica em citros, em pósemergência tardia, nos primeiros 20 DAT, em relação à mistura pronta de glyphosate $+2,4-\mathrm{D}$ a partir de $650 \mathrm{~g} \mathrm{ha}^{-1}+810 \mathrm{~g} \mathrm{ha}^{-1}$, respectivamente (Ramos e Durigan, 1996). No entanto, estes autores constataram que a senescência da trapoeraba foi acelerada pela ação do glyphosate, fato que não foi constatado onde foi aplicado 2,4-D amina isoladamente; mas, mesmo assim o glyphosate isolado não alcançou $90 \%$ de controle nem mesmo na última avaliação (91 DAT). Possivelmente, C. virginica também apresente tolerância ao herbicida glyphosate.

Ao comparar a eficiência de vários herbicidas em diferentes doses no controle de plantas daninhas em área de pousio, entre elas C. benghalensis, Borges e Bordin (1997) concluíram que glyphosate em doses acima de $360 \mathrm{~g} \mathrm{ha}^{-1}$ deu bons resultados. Kabir et al. (1991), cultivando chá na Índia, testaram, em pós-emergência, as seguintes doses de herbicidas: 2,4-D a 960, 1.200 e $1.800 \mathrm{~g} \mathrm{ha}^{-1} \mathrm{e}$ glyphosate a 610, 920 e $1.230 \mathrm{~g} \mathrm{ha}^{-1}$. Entre as principais plantas daninhas presentes estava C. benghalensis; o glyphosate foi o mais efetivo tratamento no controle de todas as espécies daninhas, particularmente a 960 e $1.230 \mathrm{~g} \mathrm{ha}^{-1}$, reduzindo de 36,8 plantas daninhas em geral por parcela (testemunha) para 5 e 3 plantas daninhas por parcela, respectivamente. Tais resultados reforçam a possibilidade de controle da espécie $C$. benghalensis com o herbicida glyphosate em aplicações isoladas, mas não foi encontrada na literatura consultada referência ao controle químico de C. diffusa.

Comparando a absorção de glyphosate entre Asclepias syriaca (suscetivel ao glyphosate) e Apocynum cannabinnum (tolerante), Wyrill e Burnside (1976) constataram que $A$. syriaca absorveu maior quantidade de glyphosate, fato atribuído, em parte, à presença de estômatos $\left(65 / \mathrm{mm}^{2}\right)$ e tricomas $\left(18 / \mathrm{mm}^{2}\right)$ na superfície adaxial da folha, elementos estes ausentes na superfície adaxial da folha da espécie tolerante.

A principal diferença entre caracteres anatômicos da superfície foliar de duas espécies de trapoeraba, observada por Santos et al. (2000), foi com relação à presença de pêlos; enquanto $C$. diffusa apresentou apenas pêlos secretores, $C$. benghalensis apresentou pêlos secretores e não-secretores (longos com extremidade afilada e curtos com extremidade curva) e maior número de pêlos em geral nas duas epidermes. De acordo com Mishra (1982), os pêlos atuam como uma plataforma para partículas do ambiente; provavelmente, então, a folha de $C$. benghalensis intercepta e mantém mais gotículas sobre a superfície do que a de C. diffusa, o que lhe proporciona maior tempo para a penetração da solução antes que ela escorra ou evapore; somando-se a isso a presença de estômatos na superfície adaxial da 
folha, é provável que $C$. benghalensis intercepte e absorva maior quantidade de glyphosate que C. diffusa. Outra hipótese para a maior sensibilidade de $C$. benghalensis ao glyphosate seria a translocação diferencial para órgãos subterrâneos. Como $C$. benghalensis produz sementes subterrâneas, a demanda de fotoassimilados para a parte subterrânea da planta é certamente maior que em C. diffusa, levando, conseqüentemente, a uma maior translocação das moléculas de herbicida para essa região.

Utilizando sais de isopropilamina de ${ }^{14} \mathrm{C}$ glyphosate e ${ }^{14} \mathrm{C}$-imazapyr, Tucker et al. (1994) concluíram que Alternanthera philoxeroides absorveu mais do dobro de imazapyr em relação à quantidade de glyphosate; a translocação de imazapyr para órgãos de reserva subterrâneos também foi maior que a do glyphosate. Por isso, os autores sugerem que essa diferença na translocação para raízes e órgãos subterrâneos seja um mecanismo de tolerância de A. philoxeroides a glyphosate e de suscetibilidade ao imazapyr.

Outro fator que pode influenciar a eficácia do tratamento herbicida é a idade e a atividade metabólica de gemas dos rizomas subterrâneos. Em Elytrigia repens, Shieh et al. (1993) observaram que baixa atividade e baixíssimos níveis de acumulação de glyphosate estavam claramente associados com gemas mais velhas, provavelmente porque estas recebem uma concentração subletal de glyphosate, o que lhes permite escapar do controle; após a morte das gemas metabolicamente mais ativas, as que receberam doses subletais voltam à atividade. O fato de rizomas subterrâneos estarem ausentes em $C$. diffusa e presentes em $C$. benghalensis poderia contribuir para explicar a maior sensibilidade da segunda ao glyphosate; soma-se a isso o fato de que, nas condições edafoclimáticas nas quais foi realizado o ensaio, $C$. benghalensis produz flores aéreas e subterrâneas praticamente o ano todo, o que leva as gemas dos rizomas subterrâneos a estar constantemente ativas.

Pelo exposto, percebe-se que a identificação da espécie de trapoeraba presente na área a ser tratada e o conhecimento de sua biologia são de fundamental importância na escolha da dose a ser aplicada, podendo significar menor volume de produto e menores custos se somente $C$. benghalensis estiver presente. Se as menores doses utilizadas neste experimento foram suficientes para controlar 100\% desta espécie no estágio adulto, certamente será mais eficiente ainda para matar plantas mais jovens, fase ideal para se realizar o controle.

Foi significativo o efeito das doses de glyphosate sobre a biomassa seca da parte aérea de plantas de C. diffusa (Tabela 4). Em geral, quanto maior a dose de glyphosate, menor a biomassa seca de C. diffusa (Figura 3 e Tabela 5); a menor dose utilizada causou redução de 58,65\% na biomassa seca em relação à testemunha; a dose de $2.880 \mathrm{~g} \mathrm{ha}^{-1}$ causou a maior redução: $84,75 \%$. Como as doses de glyphosate eliminaram todas plantas das parcelas da espécie $C$. benghalensis, excetuando a testemunha, não houve parte aérea a ser colhida e pesada, evidenciando a eficácia de todos os tratamentos, mesmo na menor dose $\left(720 \mathrm{~g} \mathrm{ha}^{-1}\right)$. Os valores registrados para peso da matéria seca da parte aérea das duas espécies reforçam a constatação da maior toxicidade de glyphosate sobre $C$. benghalensis do que sobre C. diffusa.

C. benghalensis apresentou $94,5 \%$ de controle aos 25 DAT com aplicação de $720 \mathrm{~g} \mathrm{ha}^{-1}$ de glyphosate, o que ocasionou controle total (ausência de matéria viva sobre o substrato) aos 63 DAT (Tabela 3). Mesmo com $1.300 \mathrm{~g} \mathrm{ha}^{-1}$ de glyphosate, Ramos e Durigan (1996) alcançaram no máximo $89 \%$ de controle de C. virginica aos 63 DAT e obtiveram $4,9 \mathrm{~g}$ de biomassa seca aos 98 DAT.

Tabela 4 - Análise de variância dos dados de biomassa seca da parte aérea (gramas) de plantas de Commelina diffusa, transformados (logaritmo neperiano)

\begin{tabular}{|l|c|r|r|r|}
\hline \multicolumn{1}{|c|}{ FV } & GL & \multicolumn{1}{c|}{ SQ } & \multicolumn{1}{c|}{ QM } & \multicolumn{1}{c|}{ F } \\
\hline Bloco & 5 & 0,904514 & 0,180903 & $2,33^{\text {n.s. }}$ \\
Doses & 5 & 17,045540 & 3,409109 & $43,93^{* *}$ \\
Raiz & 1 & 15,866364 & 15,866364 & $204,49^{* *}$ \\
Linear & 1 & 0,010482 & 0,010482 & $0,13^{\text {n.s. }}$ \\
Desvios & 3 & 0,895707 & 0,298569 & $3,84^{\text {n.s. }}$ \\
\hline Resíduo & 5 & 0,904514 & 0,180903 & $2,33^{\text {n.s. }}$ \\
\hline
\end{tabular}

n.s. Não-significativo a $1 \%$ de probabilidade pelo teste de F.

** Significativo a $1 \%$ de probabilidade pelo teste de $\mathrm{F}$.

$\mathrm{CV}=9,58 \%$. 
Variação na sensibilidade ao glyphosate dentro de uma mesma espécie foi relatada por Westwood et al. (1997). Estes autores observaram que o biótipo de Convolvulus arvensis tolerante a glyphosate apresentou biomassa seca estatisticamente semelhante, recebendo tanto a menor ( $\left.1.120 \mathrm{~g} \mathrm{ha}^{-1}\right)$ quanto a maior dose do ingrediente ativo (2.240 $\left.\mathrm{g} \mathrm{ha}^{-1}\right)$, enquanto a menor dose controlou eficientemente o biótipo suscetível.

Houve efeito significativo da equação de regressão (modelo raiz quadrada) do número de plântulas emergidas após a morte da parte aérea das plantas de $C$. benghalensis em função das doses de glyphosate (Tabela 6 e Figura 4). Com o uso da menor dose de glyphosate observou-se o menor número de plântulas germinadas, e com o uso de $2.160 \mathrm{~g} \mathrm{ha}^{-1}$, o maior número (Tabela 7). O controle total da parte aérea das plantas nas duas menores doses concretizou-se aos 63 DAT, enquanto nas outras doses o fato ocorreu 16 dias antes. Levanta-se como hipótese para explicar o menor número de plântulas na menor dose a

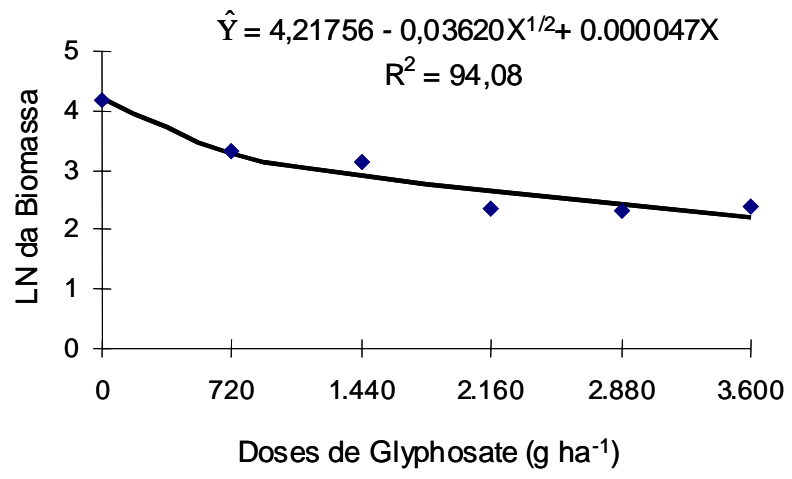

Figura 3 - Equação estimada do logaritmo neperiano da biomassa seca da parte aérea de plantas de C. diffusa, em função de doses de glyphosate. possibilidade de o produto ter se translocado mais na planta, atingindo parte das sementes subterrâneas em formação, ainda ligadas à planta-mãe, devido ao efeito mais lento do herbicida na parte aérea. Nas doses maiores, o efeito na parte aérea foi mais rápido, o que pode ter levado ao desligamento precoce da planta com as sementes subterrâneas, desencadeando o processo de superação da dormência ou reduzindo a translocação do herbicida.

Tabela 6 - Análise de variância do número de plântulas emergidas após a morte de plantas de Commelina benghalensis

\begin{tabular}{|l|c|c|c|c|}
\hline \multicolumn{1}{|c|}{ FV } & GL & SQ & QM & F \\
\hline Bloco & 5 & $7.405,887$ & $1.481,173$ & $1,62^{\text {n.s. }}$ \\
Doses & 4 & $6.353,667$ & $1.588,417$ & $1,73^{\text {n.s. }}$ \\
Raiz & 1 & $2.231,372$ & $2.231,372$ & $2,43^{\text {n.s. }}$ \\
Linear & 1 & $3.568,000$ & $3.568,000$ & $3,89^{*}$ \\
Desvios & 2 & $1.205,655$ & 602,828 & $0,66^{\text {n.s. }}$ \\
\hline Resíduo & 20 & $1.8345,13$ & 917,257 & \\
\hline
\end{tabular}

n.s. Não-significativo a $5 \%$ de probabilidade pelo teste de F.

* Significativo a $6,3 \%$ de probabilidade pelo teste de F. $\mathrm{CV}=28,21$.

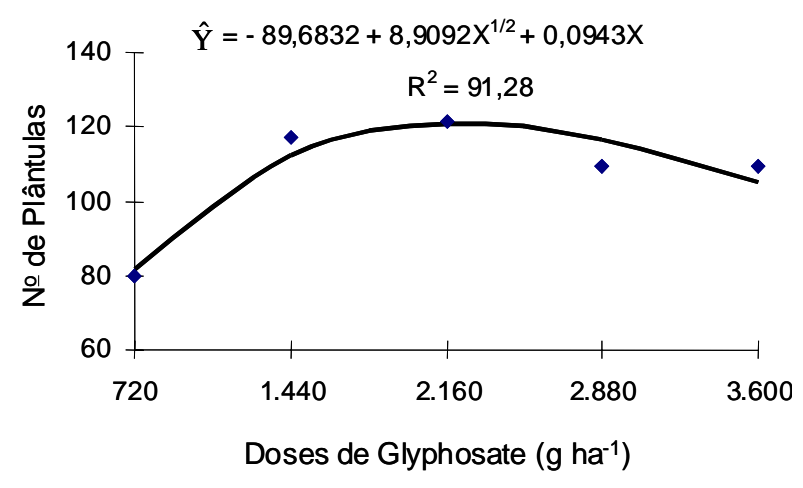

Figura 4 - Equação estimada da variável número de plântulas emergidas após a morte das plantas de C. benghalensis, em função de doses de glyphosate.

Tabela 5 - Biomassa seca da parte aérea (g/parcela) de Commelina diffusa e Commelina benghalensis, 88 dias após aplicação de glyphosate (média de seis blocos)

\begin{tabular}{|l|c|c|c|r|r|r|}
\hline \multirow{2}{*}{ Espécies de trapoeraba } & \multicolumn{7}{|c|}{ Glyphosate $\left(\mathrm{g} \mathrm{ha}^{-1}\right)$} \\
\cline { 2 - 8 } & 0 & 720 & 1.440 & 2.160 & 2.880 & 3.600 \\
\hline C. difusa & 66,28 & 27,40 & 22,96 & 10,49 & 10,10 & 10,70 \\
C. benghalensis & 29,86 & 0,00 & 0,00 & 0,00 & 0,00 & 0,00 \\
\hline
\end{tabular}


Tabela 7 - Número de plântulas emergidas numa área de $0,108 \mathrm{~m}^{2}$, após a morte de plantas de $C$. benghalensis, em função dos tratamentos (média de seis blocos)

\begin{tabular}{|c|c|}
\hline Glyphosate $\left(\mathrm{g} \mathrm{ha}^{-1}\right)$ & № de plântulas \\
\hline 720 & 79,67 \\
1.440 & 117,00 \\
2.160 & 121,17 \\
2.880 & 109,50 \\
3.600 & 109,33 \\
\hline
\end{tabular}

Lund-Høie \& Andersen (1993) investigaram o impacto da aplicação de glyphosate no estabelecimento de plantas daninhas e verificaram que o tratamento com este herbicida um ano antes de iniciar o experimento causou mudança temporária na flora recolonizadora original, do tipo perene, para flora dominada por espécies anuais. A aplicação de glyphosate criou condições favoráveis para a germinação de dicotiledôneas específicas, como Galeopsis tetrahit, Senecio vulgaris e Epilobium angustifoluim, e monocotiledôneas, como Deschampsiaflexuosa, independentemente de elas estarem presentes originalmente ou não; apesar de as razões para o efeito seletivo da aplicação de glyphosate no estabelecimento de espécies oriundas de sementes não serem conhecidas, parâmetros físicos e/ou alelopáticos devem, provavelmente, estar envolvidos. Considerando válida a constatação de Lund- Høie e Andersen (1993) para C. benghalensis, o aumento da dose de glyphosate até $6,0 \mathrm{~L} \mathrm{ha}^{-1}$ teria criado condições mais favoráveis para a germinação das sementes. $O$ fato de plântulas de trapoeraba não terem emergido durante o período de incubação do substrato, mas sim após a morte da parte aérea, é forte indício de que se tratava de sementes produzidas durante o período experimental, mais provavelmente sementes subterrâneas, já que as sementes aéreas geralmente apresentam forte dormência (Walker e Evenson, 1985). O fato de que em $0,108 \mathrm{~m}^{2}$ emergiram até 121 plântulas (Tabela 7) num período de aproximadamente 100 dias e de que essas plântulas devem representar pequena porcentagem das sementes viáveis demonstra o grande potencial de reinfestação que esta espécie apresenta.
Com base nos resultados apresentados, concluiu-se que a identificação da espécie de trapoeraba presente na área a ser tratada é de fundamental importância na escolha do produto e da dose a ser aplicada. Nas condições do experimento, C. diffusa apresentou maior tolerância ao herbicida glyphosate que $C$. benghalensis. Foi possivel o controle eficiente de $C$. benghalensis na fase reprodutiva, com aplicações isoladas de glyphosate.

\section{LITERATURA CITADA}

BARRETO, R.C. Levantamento das espécies de Commelinaceae R.Br. nativas do Brasil. São Paulo: USP - Instituto de Biociências, 1997. 490p. Tese (Doutorado em Ciências - Área de Botânica) - Universidade de são Paulo, 1997.

BORGES, E.P.; BORDIN, A.C.M. Manejo químico da área de pousio visando o plantio direto. Inf. Agron., v.79, p.10-11, 1997.

CHRISTOFFOLETI, P.J.; VICTORIA FILHO, R., SILVA, C.B. Resistência de plantas daninhas aos herbicidas. Planta Daninha, v.12, n.1, p.13-20, 1994.

DURIGAN, J.C.; GALli, A.J.B.; LEITE, G.J. Avaliação da eficiência da mistura de glyphosate e 2,4-D para o controle de plantas daninhas em citros. In: CONGRESSO BRASILEIRO DE HERBICIDAS E PLANTAS DANINHAS, 17, 1988, Piracicaba. Resumos... Piracicaba: SBEHD, 1988. p.303-304.

GALLI, A.J.B. Avaliação da eficiência de glyphosate em mistura com diversos produtos, no controle de Commelina virginica (trapoeraba) em citros. In: CONGRESSO BRASILEIRO DE HERBICIDAS E PLANTAS DANINHAS, 18, 1991, Brasília. Resumos... Brasília: SBHED, 1991. p.104-105.

KABIR, S.E.; CHAUDHURI, T.C.; HAJRA, N.G. Evaluation of herbicides for weed control in Darjeeling tea. Ind. Agric., v.35, n.3, p.179-185, 1991.

LUND-HØIE, K.; ANDERSEN, R. The impact of glyphosate application on seedling colonization in seed beds of various quality. Nor. J . Agric. Sci., v.7, p.121-128, 1993.

MALIK, J.; BARRY, G.; KISHORE, G. The herbicide glyphosate. Biofactores, v.2, p.17-25, 1989.

MISHRA, L.C. Effect of environmental pollution on the morphology and leaf epidermis of Commelina benghalensis Linn. Environ. Pollut. (Series A), v.28, p.281-284. 1982 . 
PRADO FILHO, H.P.A.; CARVALHO, F. Estudo do controle de plantas daninhas em cafezal com misturas de herbicidas pós e pré-emergentes. In: CONGRESSO BRASILEIRO DE PESQUISAS CAFEEIRAS, 8, 1980, Campos do Jordão. Resumos... Rio de Janeiro: IBC/GERCA, 1980. p.426-427.

RAMOS, H.H.; DURIGAN, J.C. Avaliação da eficiência da mistura pronta de glyphosate $+2,4-\mathrm{D}$ no controle da Commelina virginica $\mathrm{L}$ em citros. Planta Daninha, v.14, n.1, p.33-41, 1996.

SANTOS, I.C.; FERREIRA, F.A.; MEIRA, R.M.S.A.; SANTOS, L.D.T. Comparação de caracteres anatômicos entre folhas de duas espécies de Commelina invasoras de cafezais em Minas Gerais. In: CONGRESSO BRASILEIRO DA CIÊNCIA DAS PLANTAS DANINHAS, 22, 2000, Foz do Iguaçu, PR. Resumos... Londrina, PR: SBCPD, 2000. p.13.

SHIEH, W.; GEIGER, D.R.; BUCZYNSKI, S.R Distribution of imported glyphosate in quackgrass (Elytigia repens) rhizomes in relation to assimilate accumulation. Weed Sci., v.4, n. 1, p.7-11, 1993.
TUCKER, T.A.; LANGELAND, K.A.; CORBIN, F.T. Absorption and translocation of ${ }^{14} \mathrm{C}$-Imazapyr and ${ }^{14} \mathrm{C}$-Glyphosate in alligatorweed Alternanthera philoxeroides. Weed Technol., v.8, p.32-36, 1994.

VARGAS, L.; SILVA, A.A.; BORÉM, A.; REZENDE, S.T.; FERREIRA, F.A.; SEDIYAMA, T. Características da resistência de acordo com o mecanismo de ação herbicida. In: VARGAS, L.; SILVA, A.A.; BORÉM, A.; REZENDE, S.T.; FERREIRA, F.A.; SEDIYAMA, T. (Eds.) Resistência de plantas daninhas a herbicidas. Viçosa: UFV, 1999. p.16-34.

WALKER, S.R.; EVENSON, J.P. Biology of Commelina benghalensis L. in south-eastern Queensland. 2. Seed dormancy, germination and emergence. Weed Res., v.25, p.245-250, 1985.

WESTWOOD, J.H.; YERKES, C.N., DeGENNARO, F.P., WELLER, S.C. Absorption and translocation of glyphosate in tolerant and susceptible biotypes of field bindweed (Convolvulus arvensis). Weed Sci., v.45, p.658-663, 1997.

WYRILL, J.B.; BURNSIDE, O.C. Absorption, translocation, and metabolism of 2,4-D and glyphosate in common milkweed and hemp dogbane. Weed Sci., v.24, n.6, p.557-566, 1976. 